\title{
A novel recyclable furoic acid-assisted pretreatment for sugarcane bagasse biorefinery in co-production of xylooligosaccharides and glucose
}

Lin Dai ${ }^{1,2,3}$, Tian Huang ${ }^{2,3}$, Kankan Jiang $^{4}$, Xin Zhou ${ }^{1,2,3^{*}}$ (D) and Yong X $\mathrm{u}^{1,2,3}$

\begin{abstract}
Background: Pretreatment is the key step for utilizing lignocellulosic biomass, which can extract cellulose from lignin and disrupt its recalcitrant crystalline structure to allow much more effective enzymatic hydrolysis; and organic acids pretreatment with dual benefic for generating xylooligosaccharides and boosting enzymatic hydrolysis has been widely used in adding values to lignocellulose materials. In this work, furoic acid, a novel recyclable organic acid as catalyst, was employed to pretreat sugarcane bagasse to recover the xylooligosaccharides fraction from hemicellulose and boost the subsequent cellulose saccharification.

Results: The FA-assisted hydrolysis of sugarcane bagasse using $3 \%$ furoic acid at $170{ }^{\circ} \mathrm{C}$ for 15 min resulted in the highest xylooligosaccharides yield of 45.6\%; subsequently, $83.1 \mathrm{~g} / \mathrm{L}$ of glucose was harvested by a fed-batch operation with a solid loading of 15\%. Overall, a total of $120 \mathrm{~g}$ of xylooligosaccharides and $335 \mathrm{~g}$ glucose could be collected from $1000 \mathrm{~g}$ sugarcane bagasse starting from the furoic acid pretreatment. Furthermore, furoic acid can be easily recovered by cooling crystallization.

Conclusion: This work put forward a novel furoic acid pretreatment method to convert sugarcane bagasse into xylooligosaccharides and glucose, which provides a strategy that the sugar and nutraceutical industries can be used to reduce the production cost. The developed process showed that the yields of xylooligosaccharides and byproducts were controllable by shortening the reaction time; meanwhile, the recyclability of furoic acid also can potentially reduce the pretreatment cost and potentially replace the traditional mineral acids pretreatment.
\end{abstract}

Keywords: Furoic acid, Recyclable, Xylooligosaccharides, Sugarcane bagasse, Enzymatic hydrolysis

\section{Background}

Increasing demands for chemicals and energy have driven the shift toward the exploration of alternative resources; therefore low-cost and renewable lignocellulosic materials are stimulating researchers to develop techniques and methods that can convert these

\footnotetext{
*Correspondence: xinzhou@njfu.edu.cn

1 Jiangsu Co-Innovation Center of Efficient Processing and Utilization of Forest Resources, College of Chemical Engineering, Nanjing Forestry University, No. 159 Longpan Road, Nanjing 210037, People's Republic of China

Full list of author information is available at the end of the article
}

resources into high value-added products [1-3]. Sugarcane bagasse (SCB), a type of fibrous residues, can be obtained from the juice extracted from sugarcane during the sugar production process [4]. Like other fibrous residues, SCB contains high amounts of polysaccharides, especially for cellulose and hemicellulose $[5,6]$. Because of its lower ash content, the feedstock SCB has numerous advantages over other agro-based residues (such as corn stover and wheat straw); thus, it is a preferred candidate for biorefinery [7].

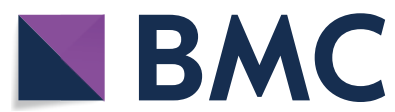

(c) The Author(s) 2021. This article is licensed under a Creative Commons Attribution 4.0 International License, which permits use, sharing, adaptation, distribution and reproduction in any medium or format, as long as you give appropriate credit to the original author(s) and the source, provide a link to the Creative Commons licence, and indicate if changes were made. The images or other third party material in this article are included in the article's Creative Commons licence, unless indicated otherwise in a credit line to the material. If material is not included in the article's Creative Commons licence and your intended use is not permitted by statutory regulation or exceeds the permitted use, you will need to obtain permission directly from the copyright holder. To view a copy of this licence, visit http://creativeco mmons.org/licenses/by/4.0/. The Creative Commons Public Domain Dedication waiver (http://creativecommons.org/publicdomain/ zero/1.0/) applies to the data made available in this article, unless otherwise stated in a credit line to the data. 
However, the native structure of $\mathrm{SCB}$, like other lignocellulosic biomasses, is strongly recalcitrant to enzymatic hydrolysis. For this reason, the implementation of the pretreatment that can deconstruct the lignocellulosic entanglement is necessary [8-10]. Thus, pretreatment is considered as the key step to deconstruct the complex structure of lignocellulose [11]. According to previous studies, acidic pretreatments, including mineral and organic acids, have been proven to effectively disrupt the recalcitrant crystalline structure of cellulose and to efficiently enhance its enzymatic hydrolysis $[12,13]$. Organic acid pretreatments are more desirable compared to dilute mineral acid pretreatments because of its many benefits in enzymatic hydrolysis, including generating lower amounts of degradation products and ability to directly generate value-added products like xylooligosaccharides (XOS) [14-16]. XOS are particularly attractive products because of their potential function in enhancing human immunity and promoting the growth of bifidobacteria and lactobacillus [17-19]. Concurrent production of $\mathrm{XOS}$ and fermentable sugars can effectively improve economic efficiency of SCB biorefinery [20]. However, the separation of acid catalyst and the recovery of product after the acid pretreatment are still challenging due to not only the technical issues, but also the economic problems. Therefore, it is urgent to speed up the technological innovation that can help augment the utilization and processing of SCB resources.

Furoic acid (FA) as a recyclable organic acid was first employed for producing XOS and pretreating SCB material. FA is a heterocyclic carboxylic acid, consisting of a five-membered aromatic ring and a carboxylic acid group and has been widely used in food products as preservative and flavoring agent; its solubility is only $37 \mathrm{~g} / \mathrm{L}$ in $25^{\circ} \mathrm{C}$ water and it is easily recovered by cooling and natural crystallization [21]. In the present study, we designed an integrated biorefinery process, which using FA as catalyst for xylan degradation and as a pretreatment agent-a part of the attempts to develop a new biorefinery process, starting from FA pretreatment.

\section{Results and discussion}

Influence of FA concentration, and hydrolysis temperature and time on conversion of hemicelluloses

In an acid-hydrolysis process, xylan was first degraded into polysaccharides with high degree of polymerization (DP); and these polysaccharides would be further degraded into oligomers with low DP or xylose [14]. As a result, in the presence of acid catalyst, the XOS and xylose yields increased gradually with increasing reaction temperature and hydrolysis time. However, as retention time was further prolonged, XOS also could be degraded into xylose and furfural. Therefore, a suitable reaction condition is required so as to achieve the highest XOS yield. Three main parameters that affect both the degradation rate and the selectivity, including FA concentration (1-3\%), hydrolysis time (15-60 min) and hydrolysis temperature $\left(130-170{ }^{\circ} \mathrm{C}\right)$, were investigated [7], and the results, presented as yields of furfural, xylose and XOS with a DP range of 2-6, are displayed in Fig. 1a-c.

As can be observed in Fig. 1, both the hydrolysis temperature and hydrolysis time significantly affected the XOS yield. At relatively low reaction temperature and short hydrolysis time, the XOS yield was very low: the XOS yield produced by the use of 3\% FA for $15 \mathrm{~min}$ at $130{ }^{\circ} \mathrm{C}$ was only $1.09 \%$. It can also be seen that the XOS yield was significantly enhanced when the hydrolysis time was increased from 15 to 60 min: the XOS yield generated by the use of 3\% FA for 60 min was $16.3 \%$. According to the chromatogram, some xylo-saccharides with sizes of larger than X6 could not be degraded into $\mathrm{XOS}$ at a low temperature. Conversely, xylan was easy to be hydrolyzed into soluble polymers with lower molecular weights at high temperature. Figure $1 \mathrm{a}$ and $\mathrm{b}$ show that the XOS yield rapidly increased from $3.9 \%\left(130{ }^{\circ} \mathrm{C}\right.$, $3 \% \mathrm{FA}, 30 \mathrm{~min})$ to $28.9 \%\left(150{ }^{\circ} \mathrm{C}, 3 \% \mathrm{FA}, 30 \mathrm{~min}\right)$; similar observation was also observed when the hydrolysis temperatures were $150{ }^{\circ} \mathrm{C}$ and $170{ }^{\circ} \mathrm{C}$, in which the XOS yield was rapidly increased from $8.1 \%\left(150{ }^{\circ} \mathrm{C}, 3 \%\right.$ FA, $15 \mathrm{~min})$ to $46.5 \%\left(170{ }^{\circ} \mathrm{C}, 3 \% \mathrm{FA}, 15 \mathrm{~min}\right)$. In addition, too long hydrolysis time resulted in a markedly decline in XOS content, which could be ascribed to the further degradation of some XOS under such harsh reaction conditions. Thus, we observed that XOS yield at both 150 and $170{ }^{\circ} \mathrm{C}$ first increased and then decreased, and with prolonged hydrolysis time and higher temperature, higher amounts of X2 and X3 and lower amounts of $\mathrm{X} 5$ and $\mathrm{X} 6$ were obtained. Using 3\% FA as the catalyst, a remarkable decrease in XOS yield at $170{ }^{\circ} \mathrm{C}$ from $46.5 \%$ (15 $\mathrm{min})$ to $38.1 \%$ (60 $\mathrm{min}$ ) was observed; and accordingly, a rapid increase of xylose and furfural yields was observed.

Taken together, in the case of the low reaction temperature, it required a relatively long hydrolysis time and it is economically unfavorable. However, longer hydrolysis time resulted in further hydrolysis of oligosaccharides into smaller molecules byproducts, xylose and furfural. Although similar XOS yields (44.4 versus $46.5 \%$ ) were obtained at 150 and $170{ }^{\circ} \mathrm{C}$ at 60 and $15 \mathrm{~min}$, it could be observed that the yields of xylose and furfural with a hydrolysis time of $60 \mathrm{~min}$ were significantly higher than that of $15 \mathrm{~min}$. Apparently, the longer reaction time resulted in higher by-products (xylose and furfural) yields. These results indicate that the production of XOS and byproducts in the FA-assisted hydrolysis process can be controlled by changing FA concentration, hydrolysis 

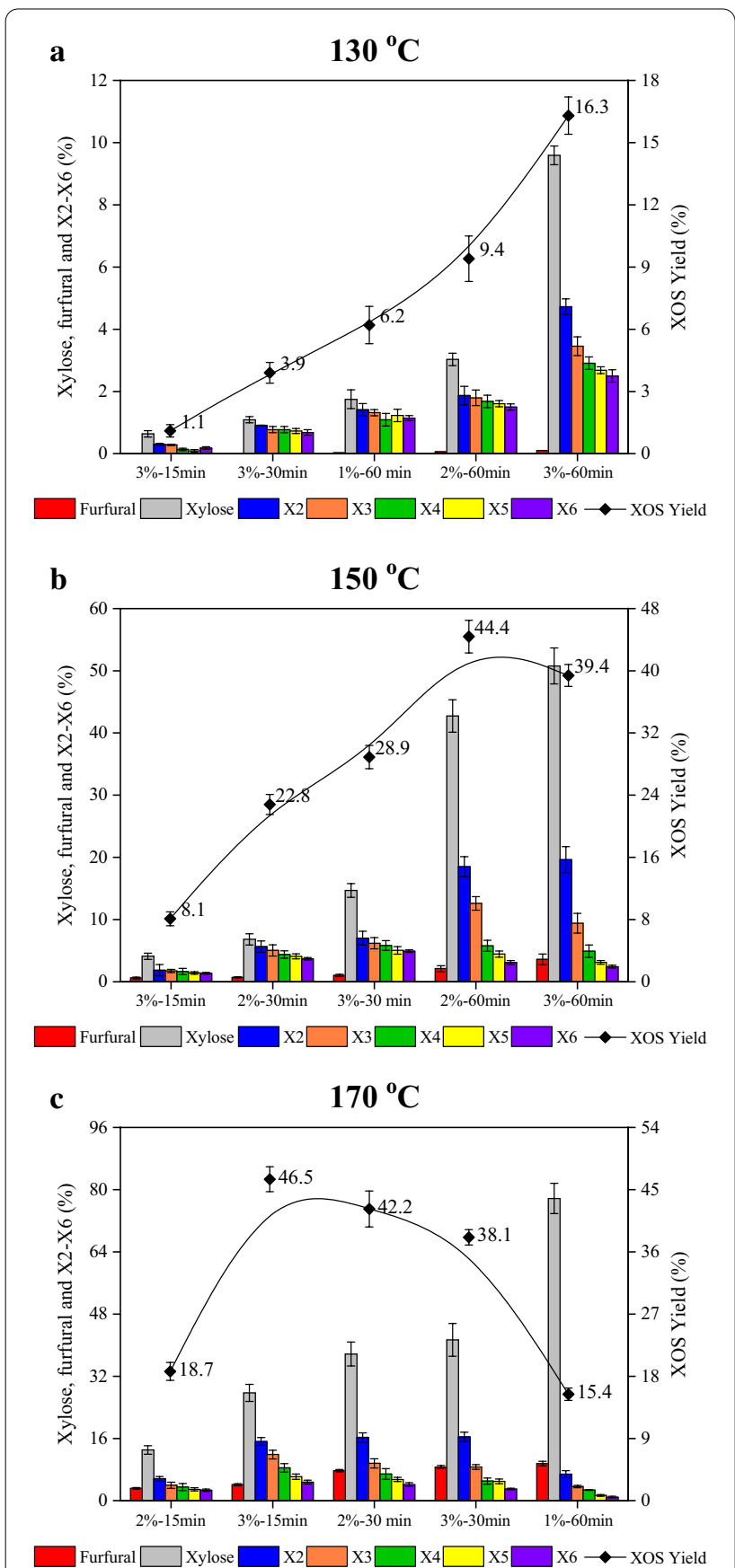

Fig. 1 Yields of furfural, xylose, X2-X6, and XOS in hydrolysate of SCB pretreated with different concentrations of FA for varying durations at different temperatures: a $130^{\circ} \mathrm{C} ; \mathbf{b} 150{ }^{\circ} \mathrm{C}$; and $\mathbf{c} 170{ }^{\circ} \mathrm{C}$

temperature and reaction time. It has been accepted that a high reaction temperature with short hydrolysis time is much more conducive to the formation of oligosaccharides with lower by-product yields. Optimization of the assays showed that the highest content of XOS generated $\left(170{ }^{\circ} \mathrm{C}\right.$ for $15 \mathrm{~min}$ with $\left.3 \% \mathrm{FA}\right)$ was $11.9 \mathrm{~g} / \mathrm{L}(3.77 \mathrm{~g} / \mathrm{L} \mathrm{X} 2$,
$3.04 \mathrm{~g} / \mathrm{L} \mathrm{X} 3,2.45 \mathrm{~g} / \mathrm{L} \mathrm{X} 4,1.54 \mathrm{~g} / \mathrm{L} \mathrm{X} 5$ and $1.11 \mathrm{~g} / \mathrm{L} \mathrm{X6)}$ with a yield of $46.5 \%$

\section{Furoic acid recovery}

Nowadays, green and sustainable development, which aims to balance the environment/resource and economic growth, is a matter of significant importance facing all countries. Thus, a required appeared to re-design the processes for preventing hazardous chemical syntheses, minimizing wastes and increasing efficiency. The use of stronger maleic acid $\left(\mathrm{H}_{2} \mathrm{SO}_{4}\right.$ or $\left.\mathrm{HCl}\right)$ for pretreating $\mathrm{SCB}$ might result in lower catalyst loading and short reaction time, but it is not suitable for recycling and repeated extractions because of the environmentally hazardous and costly [13]. In contrast, FA is a heterocyclic monocarboxylic acid with a low water-solubility, thus rendering it can be easily extracted and recovered for further reuse, mostly by using the natural crystallization method of cooling the acid liquor.

After being separated by filtration, the acid liquor was triple-concentrated through rotary vacuum evaporation, and the concentrated hydrolysate was then refrigerated overnight at $4{ }^{\circ} \mathrm{C}$, then $95 \%$ FA crystallized and gradually precipitated. In order to determine whether the acid remained unaffected, HPLC analysis was initially used to determine the change of the FA. In addition, FTIR was also applied to analyze the FA crystals and to compare them with the crystals of the FA standards. The HPLC results confirmed that the peak of the collected crystals was the same as that of the standard and the content of FA after hydrolysis showed almost no lose. As shown in Fig. 2, the FTIR spectra showed that there were no significant differences between the crystals of FA and those of the standard [22]. The results of both HPLC and FTIR analyses confirmed both the identity and the purity of

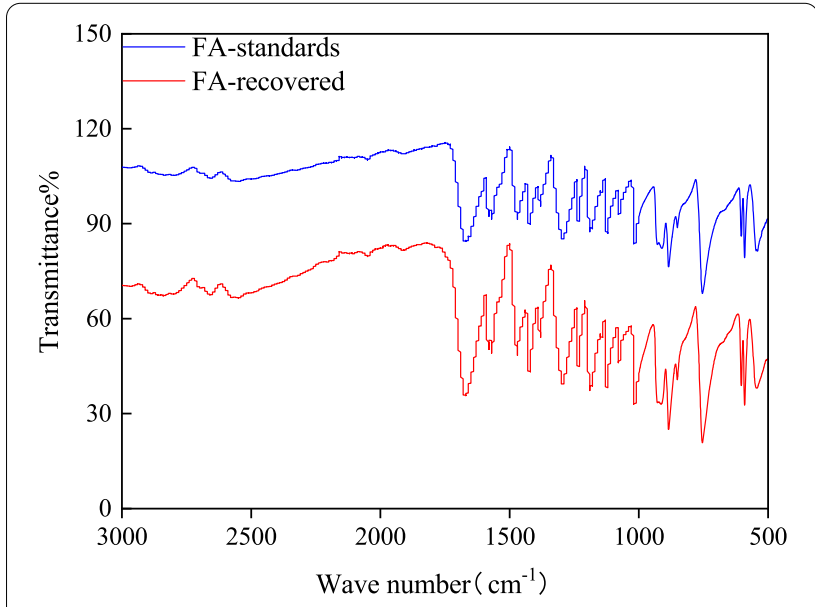

Fig. 2 FTIR spectra of standard and recovered furoic acid 
FA, indicating that the recovered FA was identical to the FA standards, thus it may suitably be recycled in additional hydrolysis rounds.

\section{Enzymatic hydrolysis of pretreated solid residues}

It is known that crystallinity of cellulose can highly impact its enzymatic digestibility. XRD analysis (Fig. 3) showed that the characteristic peak of cellulose I at $2 \theta=21.9^{\circ}$ were observed in both the un-pretreated biomass and the FApretreated biomass. The CrI, which is the ratio between the crystalline portion in cellulose to the amorphous portion, of the FA-pretreated sample (48.8\%) increased compared to that of the un-pretreated sample (34.3\%). The increase of $\mathrm{CrI}$ is mainly attributed to get rid of amorphous hemicellulose. The removal of the xylan-riched hemicellulose and lignin can break the entanglement of cellulose, hemicellulose and lignin, and improve the accessibility of cellulases to cellulose. The XRD results indicated that the pretreatment with FA could increase the cellulose portion availability of SCB, suggesting that it can increase the cellulolytic digestibility of SCB in the same manner as the other pretreatment methods [23, 24]. Furthermore, the SEM (Fig. 4) images showed that the surface of un-pretreated raw SCB is smooth and compact. After FA pretreatment, the surfaces of pretreated SCB appeared rough and etched, and seem to feature much more newly exposed surfaces. Larger exposed surface areas and more micropore quantities that occurred in FA-pretreated SCB offer more probability for the action of cellulases [25]. Altogether, FA-assisted prehydrolysis is a feasible and promising pretreatment method for further processing SCB.

After the pretreatment with $3 \%$ FA, $85 \%$ of xylan was removed from $\mathrm{SCB}$, while XOS was directly converted into a liquid phase, causing the content of glucan in the pretreated solid residues to increase from 42.7 to $62.1 \%$;

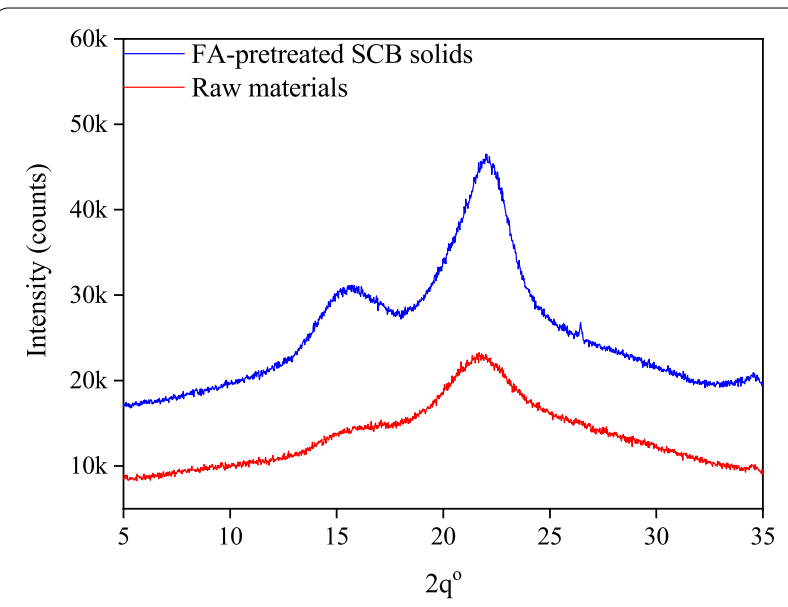

Fig. 3 XRD patterns obtained from the un-pretreated raw material and FA-pretreated SCB solids
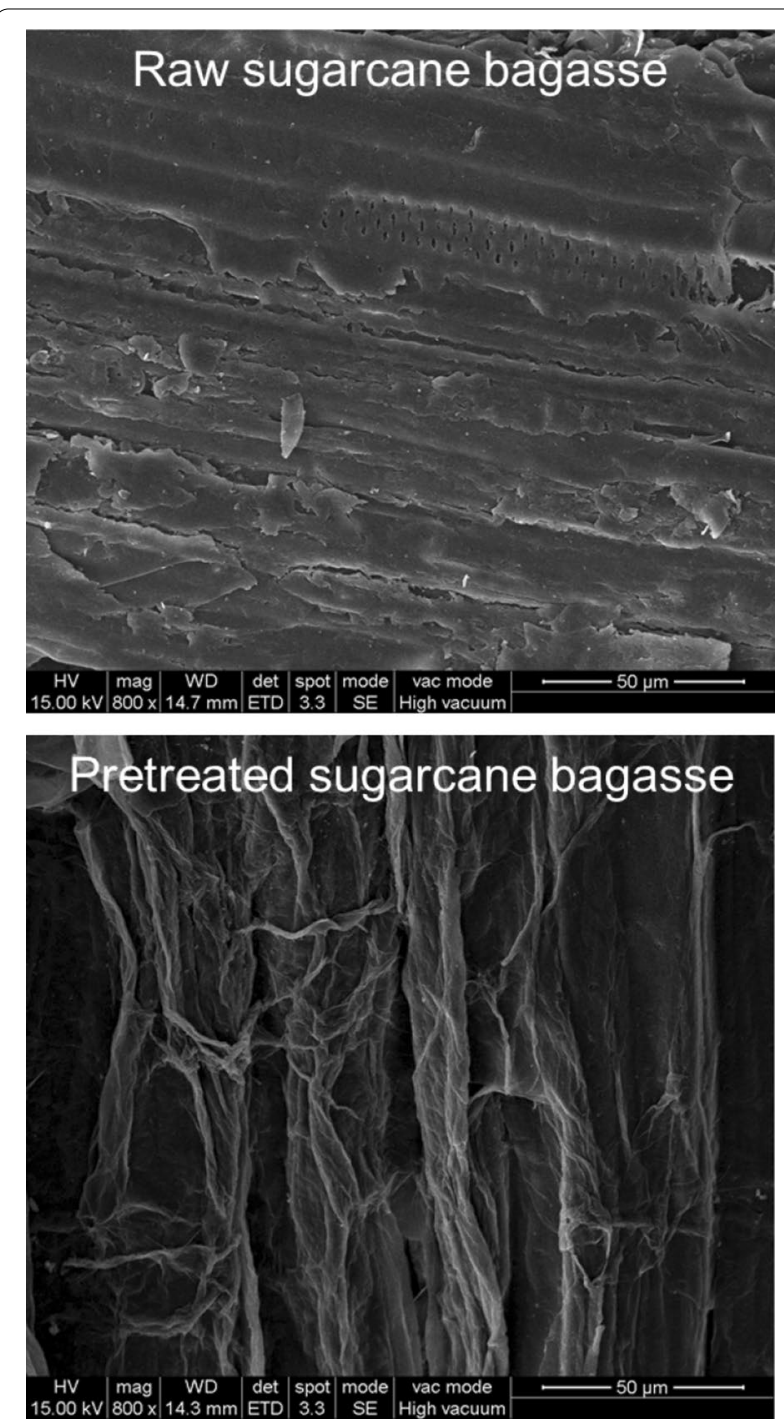

Fig. 4 Scanning electron micrographs (SEM) of pretreated and untreated sugarcane bagasse solid

and most of the glucan (88.6\%) was reserved. The reserved glucan can usually be degraded into glucose, which is easy to be transformed into biofuels or other biochemical compounds; however, it is well known that the activity of cellulases will be inhibited by inhibitors from degradation, such as formic acid, furfural, and HMF, as well as by lignin derivatives (phenolic compounds). Thus, prior to the enzymatic hydrolysis process, the pretreated solids were firstly rinsed with water to get rid of the inhibitors [26]. Moreover, increasing the solids loading not only can enhance the final fermentable glucose concentration, but also reduce the overall production cost by reducing the equipment size, the associated energy consumption, and the burdens of 
the downstream processing. Therefore, a higher solid loading is preferred in process of enzymatic hydrolysis; and based on that, batch and fed-batch hydrolysis using varying solid loadings $(5,10,15$, and $20 \% \mathrm{w} / \mathrm{v})$ to produce high-concentration glucose was conducted. In this assay, the Cellic CTec 2 enzyme at a dose of 20 FPIU/g glucan was used; this enzyme contains a certain amount of $\beta$-glucosidase; therefore, $\beta$-glucosidase was not additionally added into the assay.

The course of glucose production depicted in Fig. 5a showed that the solid loading had a direct link with the glucose concentration in each enzymatic hydrolysate. After $96 \mathrm{~h}$ of reaction, glucose at concentrations of 31.2, $58.7,66.3$, and $71.2 \mathrm{~g} / \mathrm{L}$ was released from the reaction with solid loadings of $5,10,15$ and $20 \%$, respectively. However, as can be seen, the solid in the system containing $5-10 \%$ solid loadings was liquefied within $6-12 \mathrm{~h}$, and the relationship between the glucose concentration and the solid loading was nearly linear. On the other hand, the time of liquefaction of the system with the solid loadings of $15-20 \%$ was retarded to over $12 \mathrm{~h}$, and the

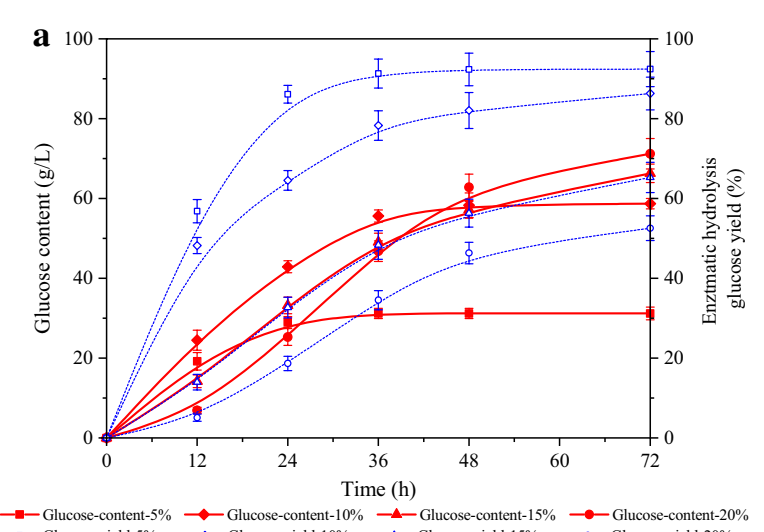

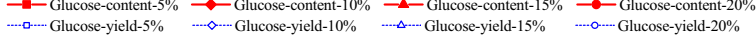

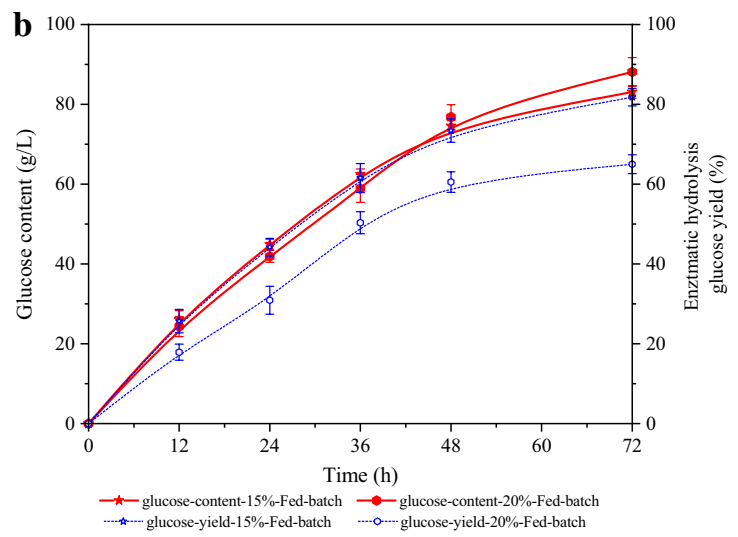

Fig. 5 Performance of a batch enzymatic hydrolysis using 5-20\% solid loadings; and $\mathbf{b}$ fed-batch enzymatic hydrolysis using 15 and $20 \%$ solid loadings hydrolysis rate was also very slow. Yields of 90.8, 90.2, 74.2 , and $63.1 \%$ were obtained from the system with the solid loadings of $5,10,15$, and $20 \%$, respectively. It can also be observed that the hydrolysis rate was high in the first $12 \mathrm{~h}$; this could be explained by the reduction of the crystallinity and the increase of the available catalytic sites [27]. It is apparent that high hydrolysis consistency may result in difficulties in stirring the material due to high viscosity as a result of high solid loadings and the lack of free water in the system, which can limit the mass transfer; these events lead to product accumulation [28, 29].

Higher solid loadings can therefore lead to the decrease in glucose yield. When the solid loading was over $15 \%$, there was a considerable amount of cellulose in the pretreated residue that was not hydrolyzed. Therefore, it could be concluded that $10 \%$ solid loading was the initial loading optimal for batch operation, according to the change of glucose concentration and the time of liquefaction. However, the glucose concentration was only $57 \mathrm{~g} / \mathrm{L}$ when the solid loading was $10 \%$. High ethanol concentration $(>4 \%, v / v)$ is one of the prerequisites that enable the industrial-scale ethanol distillation to be economically viable. Thus, it is necessary that glucose obtained from the enzymatic hydrolysis should over $80 \mathrm{~g} / \mathrm{L}$; this also indicates that the loading of the solid biomass that usually contains $40 \%$ 60 glucan should be over $15 \%$ to sufficiently achieve the available fermentable sugars [30]. However, the slurry of the fibrous material with high solid loadings has high apparent viscosity, which can result in poor mixing, as well as poor mass and enzyme distribution and poor heat transfer, causing the reduce of the enzymatic efficiency. One approach that can minimize these negative effects is by conducting fed-batch enzymatic hydrolysis [30].

Thus, we carried out fed-batch enzymatic hydrolysis of FA-pretreated SCB to produce glucose with high-concentration. As presented in Fig. 5b, 83.1 and 88.1 g/L glucose could be obtained, respectively, with fed-batch enzymatic hydrolysis of 15 and $20 \%$ solids loading. Apparently, at the same solid loading of $15 \%$, hydrolysis time required for the fed-batch mode was lower than that required for the batch mode. At the fed-batch solid loading mode, although the glucose conversion decreased in both cases, the decrease in fed-batch mode was lower than that in batch mode, which still demonstrates that the fed-batch mode is an excellent way to produce high-concentration fermentable sugars. Altogether, the fed-batch hydrolysis could weaken the negative effects such as low free water content, poor mixing, and product inhibition, thus could enable the production of high glucose concentrations at high solid loadings. In addition, $88.1 \mathrm{~g} / \mathrm{L}$ glucose could be 
obtained from $20 \%$ solids loading with fed-batch operation, but at a lower yield of $65.1 \%$. Taken together, a fedbatch enzymatic hydrolysis of FA-pretreated SCB with $15 \%$ solid loading within $72 \mathrm{~h}$ is preferable for producing high-concentration fermentable glucose.

Finally, the mass balances of the integrated process for $\mathrm{XOS}$ and glucose production were systematically calculated, as depicted in Fig. 6, approximately $120 \mathrm{~g} \mathrm{XOS}$ and $335 \mathrm{~g}$ glucose products could be collected from $1000 \mathrm{~g}$ oven-dried SCB (containing $427 \mathrm{~g}$ glucan and $256 \mathrm{~g}$ xylan) starting from FA pretreatment. In aggregate, the recovery rates of xylan and glucan were 46.5 and $71.3 \%$, respectively. The experimental findings suggest that FA pretreatment could be a promising and profitable option for the concurrent maximization of the economic value of SCB.

\section{Conclusion}

In this study, a novel FA pretreatment method that can be applied in XOS and glucose production was developed. The optimal pretreatment conditions, which resulted in the highest XOS yield of $46.5 \%$, were $3 \% \mathrm{FA}, 170{ }^{\circ} \mathrm{C}$, and $15 \mathrm{~min}$. The fed-batch enzymatic hydrolysis of FApretreated SCB could successfully produce high concentration of glucose, which is over $8 \%$. Overall, a total of $120 \mathrm{~g}$ of XOS and $335 \mathrm{~g}$ glucose were collected from $1000 \mathrm{~g}$ SCB starting from recyclable FA pretreatment. It is a strategy that the sugar and nutraceutical industries can be used to reduce the production cost.

\section{Materials and methods}

\section{Raw materials and chemical composition analysis}

SCB was harvested in October 2019 from Hainan Province, China. The harvested SCB was air-dried, milled, and then passed through 60 meshes; the obtained ground SCB was used as feedstock for subsequent processes. The chemical composition (wt\%, oven-dry-weight basis) of SCB was: glucan, $42.7 \%$; xylan, $25.6 \%$; lignin, $24.8 \%$; ash, $2.06 \%$. The chemical composition of SCB was analyzed by the two-step sulfuric acid hydrolysis method, which is supported by the National Renewable Energy Laboratory (NREL) [31].

\section{Hydrolysis of sugarcane bagasse by furoic acid}

SCB $(3.0 \pm 0.03 \mathrm{~g})$ was mixed with $30 \mathrm{~mL}$ of $1-3 \%$ FA solution and loaded in a $50-\mathrm{mL}$ stainless steel tube reactor, which was then immersed in preheated oil baths at $130-170{ }^{\circ} \mathrm{C}$ for $15-60 \mathrm{~min}$; after the hydrolysis reaction was completed, the reactor was immediately removed from the oil bath and cooled down to room temperature. The resultant solid and liquid fractions were separated by filtration; and the solids were then subjected to enzymatic hydrolysis process [32].

\section{Batch and fed-batch enzymatic hydrolysis}

Prior to enzymatic hydrolysis, the solid residues from the FA pretreatment were washed with distilled water and then air-dried to a constant weight (the moisture content was $7.6 \%$ ). Both batch and fed-batch enzymatic hydrolysis assays were conducted in a screw capped bottles $(250 \mathrm{~mL})$ shaken at $150 \mathrm{rpm}$ at $50{ }^{\circ} \mathrm{C}$ for $72 \mathrm{~h}$ : each bottle contained $50 \mathrm{~mL}$ sodium citrate buffer $(0.05 \mathrm{~mol} / \mathrm{L}$, $\mathrm{pH} 4.8$ ), and a constant cellulase concentration of 20 FPIU/g glucan (Cellic CTec2, Novozymes, NA, Franklinton, USA) was added into enzymatic hydrolysis system according to different solid loadings (5, 10, 15, and 20\%). After enzymatic hydrolysis, the slurry was subjected to centrifugation for collecting supernatant. Fed-batch enzymatic hydrolysis was conducted with $5 \%(\mathrm{w} / \mathrm{v})$ of solids ( $2.5 \mathrm{~g}$ dry weight) and enzymes; the two components (solids and cellulase) were simultaneously added into the

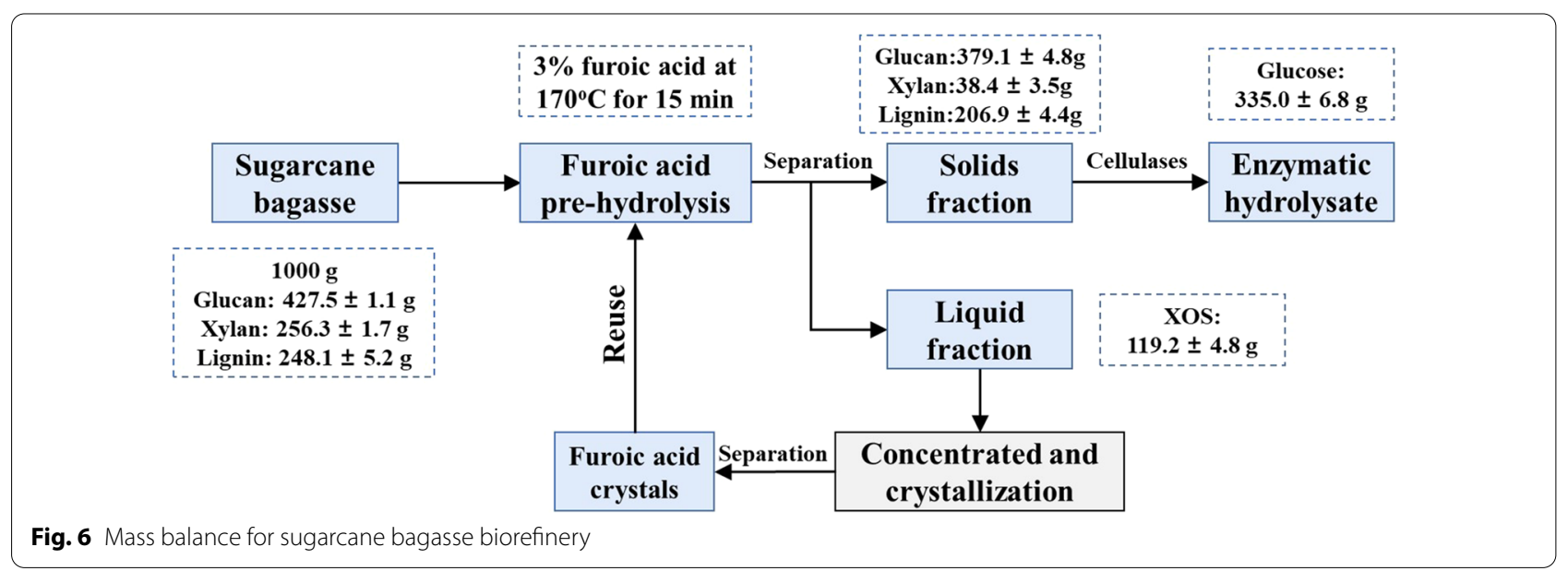


hydrolysis reaction system every $6 \mathrm{~h}$ at the desired loadings $[28,30]$.

\section{Recovery of furoic acid from the hydrolysate}

After being separated by filtration, the acid liquor was triple-concentrated by rotary vacuum evaporation (RV10, IKA, Germany), and the concentrated hydrolysate was then refrigerated overnight at $4{ }^{\circ} \mathrm{C}$ to allow FA to gradually crystallize and precipitate. The FA crystals were recovered by filtration through a glass fiber filter and were then compared with the crystals of the FA standard using Fourier transform infrared (FTIR) spectroscopy (Tensor 27-IR, Bruker, USA).

\section{Analysis of crystallinity of cellulose by X-ray diffraction}

The crystallinity index (CrI) and the crystal size of cellulose from unpretreated and FA-pretreated SCB solids were analyzed by X-ray diffraction (XRD) at a voltage of $40 \mathrm{kV}$ and a current of $40 \mathrm{~mA}$. The data were collected from $5^{\circ}$ to $50^{\circ}$ at a $10^{\circ} / \mathrm{min}$ scanning rate. The CrI was calculated as the followed equation:

$$
\operatorname{CrI}(\%)=\frac{\mathrm{A}_{\text {cryst }}}{\mathrm{A}_{\text {cryst }}+\mathrm{A}_{\text {amorph }}} \times 100 \%,
$$

where $A_{\text {cryst }}$ is the area under curve of the crystalline cellulose and $\mathrm{A}_{\text {amorph }}$ is the area under curve of the amorphous cellulose [24].

\section{Analytical methods}

Furfural and FA were analyzed by a high-performance liquid chromatograph (HPLC; Agilent 1260, USA) equipped with an Aminex Bio-Rad HPX-87H column (Bio-Rad Laboratories, USA); xylose, xylobiose (X2), xylotriose (X3), xylotetraose (X4), xylopentaose (X5), and xylohexaose (X6) were co-analyzed by a high-performance anion exchange chromatograph (Dionex ICS3000, USA) coupled to a CarboPac ${ }^{\mathrm{TM}}$ PA200 column [33].

\begin{abstract}
Abbreviations
SCB: Sugarcane bagasse; XOS: Xylooligosaccharides; XA: Xylonic acid; SB: Sugarcane bagasse; XA.Na: Sodium xylonite; DP: Degrees of polymerization; X2: Xylobiose; X3: Xylotriose; X4: Xylotetraose; X5: Xylopentaose; X6: Xylohexose; X7: Xyloheptaose; X8: Xylononylose; FTIR: Fourier transform infrared; Crl: Crystallinity index; XRD: X-ray diffraction; HPLC: High-performance liquid chromatography; HPAEC: High-performance anion exchange chromatography.
\end{abstract}

\section{Acknowledgements}

The authors acknowledge the financial support of National Key R\&D Program of China. The research would also like to acknowledge the start-up funds for scientific research.

\section{Authors' contributions}

$X Z$ and $Y X$ developed the idea for the study, performed the research and data analysis, and prepared the manuscript. LD and TH performed the research and data analysis. KJ helped to analyze data and revise the manuscript. All authors read and approved the final manuscript.

\section{Funding}

This study was funded by the National Key R\&D Program of China (2017YFD0601001), the National Natural Science Foundation of China (31901270), and the Scientific Research Start-up Funds of Nanjing Forestry University, China (163030127).

Availability of data and materials

All data generated or analyzed during this study are included in this published article.

\section{Ethics approval and consent to participate}

Not applicable.

\section{Consent for publication}

Not applicable.

\section{Competing interests}

The authors declare that they have no competing interests.

\section{Author details}

${ }^{1}$ Jiangsu Co-Innovation Center of Efficient Processing and Utilization of Forest Resources, College of Chemical Engineering, Nanjing Forestry University, No. 159 Longpan Road, Nanjing 210037, People's Republic of China. ${ }^{2}$ Key Laboratory of Forestry Genetics \& Biotechnology (Nanjing Forestry University), Ministry of Education, Nanjing 210037, People's Republic of China. ${ }^{3}$ Jiangsu Province Key Laboratory of Green Biomass-Based Fuels and Chemicals, Nanjing 210037, People's Republic of China. ${ }^{4}$ School of Basic Medical Sciences and Forensic Medicine, Hangzhou Medical College, Hangzhou 310053, People's Republic of China.

Received: 16 November 2020 Accepted: 13 December 2020 Published online: 02 February 2021

References

1. Himmel ME, Ding S, Johnson DK, Adney WS, Nimlos MR, Brady JW, Foust TD. Biomass recalcitrance: engineering plants and enzymes for biofuels production. Science. 2007;315(5813):804-7.

2. Zhao Z, Huang C, Wu D, Chen Z, Zhu N, Gui C, Zhang M, Umemura $\mathrm{K}$, Yong Q. Utilization of enzymatic hydrolysate from corn stover as a precursor to synthesize an eco-friendly plywood adhesive. Ind Crop Prod. 2020;152:112501.

3. Chen J, Fan X, Zhang L, Chen X, Sun S, Sun R. Research progress in lignin-based slow/controlled release fertilizer. Chemsuschem. 2020;13(17):4356-66.

4. Chacón SJ, Matias G, Vieira CFDS, Ezeji TC, Maciel Filho R, Mariano AP. Enabling butanol production from crude sugarcane bagasse hemicellulose hydrolysate by batch-feeding it into molasses fermentation. Ind Crop Prod. 2020:155:112837.

5. Yu N, Tan L, Sun Z, Nishimura H, Takei S, Tang Y, Kida K. Bioethanol from sugarcane bagasse: focused on optimum of lignin content and reduction of enzyme addition. Waste Manage. 2018;76:404-13.

6. Jugwanth Y, Sewsynker-Sukai Y, Gueguim Kana EB. Valorization of sugarcane bagasse for bioethanol production through simultaneous saccharification and fermentation: optimization and kinetic studies. Fuel. 2020;262:116552

7. Zhang W, You Y, Lei F, Li P, Jiang J. Acetyl-assisted autohydrolysis of sugarcane bagasse for the production of xylo-oligosaccharides without additional chemicals. Bioresource Technol. 2018;265:387-93.

8. Cui L, Li J, Wei X, Tang B, Chang G, Wu H. Comparative study of three pretreatment methods on sugarcane bagasse. In: Kim YH, editor. AERAdvances in Engineering Research. 2017. p 989-93.

9. Ilanidis D, Stagge S, Jönsson LJ, Martín C. Effects of operational conditions on auto-catalyzed and sulfuric-acid-catalyzed hydrothermal pretreatment of sugarcane bagasse at different severity factor. Ind Crop Prod. 2021;159:113077.

10. Wei W, Wang B, Wang $X$, Ling R, Jin Y. Comparison of acid and alkali catalyzed ethylene glycol organosolv pretreatment for sugar production from bagasse. Bioresource Technol. 2021;320:124293. 
11. Huang C, Zheng Y, Lin W, Shi Y, Huang G, Yong Q. Removal of fermentation inhibitors from pre-hydrolysis liquor using polystyrene divinylbenzene resin. Biotechnol Biofuels. 2020. https://doi.org/10.1186/s1306 8-020-01828-3.

12. Jonglertjunya W, Makkhanon W, Siwanta T, Prayoonyong P. Dilute acid hydrolysis of sugarcane bagasse for butanol fermentation. Chiang Mai J Sci. 2014;41(1):60-70.

13. Ríos-González LJ, Medina-Morales MA, Rodríguez-De La Garza JA, Romero-Galarza A, Medina DD, Morales-Martínez TK. Comparison of dilute acid pretreatment of agave assisted by microwave versus ultrasound to enhance enzymatic hydrolysis. Bioresource Technol. 2021:319:124099.

14. Lin Q, Li H, Ren J, Deng A, Li W, Liu C, Sun R. Production of xylooligosaccharides by microwave-induced, organic acid-catalyzed hydrolysis of different xylan-type hemicelluloses: optimization by response surface methodology. Carbohyd Polym. 2017;157:214-25.

15. Zhang $H, X u Y, Y u S$. Co-production of functional xylooligosaccharides and fermentable sugars from corncob with effective acetic acid prehydrolysis. Bioresource Technol. 2017;234:343-9.

16. Cesaro A, Conte A, Carrère H, Trably E, Paillet F, Belgiorno V. Formic acid pretreatment for enhanced production of bioenergy and biochemicals from organic solid waste. Biomass Bioenerg. 2020;133:105455.

17. Carvalho AFA, Figueiredo FCD, Campioni TS, Pastore GM, de Oliva NP. Improvement of some chemical and biological methods for the efficient production of xylanases, xylooligosaccharides and lignocellulose from sugar cane bagasse. Biomass Bioenerg. 2020;143:105851.

18. Huang $C$, Wang $X$, Liang $C$, Jiang $X$, Yang $G, X u$ J, Yong Q. A sustainable process for procuring biologically active fractions of high-purity xylooligosaccharides and water-soluble lignin from Moso bamboo prehydrolyzate. Biotechnol Biofuels. 2019. https://doi.org/10.1186/s1306 8-019-1527-3.

19. Quiñones TS, Retter A, Hobbs PJ, Budde J, Heiermann M, Plöchl M, Ravella SR. Production of xylooligosaccharides from renewable agricultural lignocellulose biomass. Biofuels. 2015;6(3-4):147-55.

20. Zhang J, Xie J, Zhang H. Sodium hydroxide catalytic ethanol pretreatment and surfactant on the enzymatic saccharification of sugarcane bagasse. Bioresource Technol. 2021;319:124171.

21. Yang $D, M a C$, Peng B, Xu J, He Y. Synthesis of furoic acid from biomass via tandem pretreatment and biocatalysis. Ind Crop Prod. 2020. https://doi org/10.1016/j.indcrop.2020.112580.

22. Peretz R, Sterenzon E, Gerchman Y, Kumar Vadivel V, Luxbacher T, Mamane H. Nanocellulose production from recycled paper mill sludge using ozonation pretreatment followed by recyclable maleic acid hydrolysis. Carbohyd Polym. 2019;216:343-51.

23. Lin W, Xing S, Jin Y, Lu X, Huang C, Yong Q. Insight into understanding the performance of deep eutectic solvent pretreatment on improving enzymatic digestibility of bamboo residues. Bioresource Technol. 2020;306:12163.

24. Ling Z, Guo Z, Huang C, Yao L, Xu F. Deconstruction of oriented crystalline cellulose by novel levulinic acid based deep eutectic solvents pretreatment for improved enzymatic accessibility. Bioresour Technol. 2020;305:123025

25. Rollin JA, Zhu Z, Sathitsuksanoh N, Zhang YH. Increasing cellulose accessibility is more important than removing lignin: a comparison of cellulose solvent-based lignocellulose fractionation and soaking in aqueous ammonia. Biotechnol Bioeng. 2011;108(1):22-30.

26. Rajan K, Carrier DJ. Effect of dilute acid pretreatment conditions and washing on the production of inhibitors and on recovery of sugars during wheat straw enzymatic hydrolysis. Biomass Bioenerg. 2014;62:222-7.

27. Cheng M, Kadhum HJ, Murthy GS, Dien BS, Singh V. High solids loading biorefinery for the production of cellulosic sugars from bioenergy sorghum. Bioresource Technol. 2020;318:124051.

28. Martins LHDS, Rabelo SC, Costa ACD. Effects of the pretreatment method on high solids enzymatic hydrolysis and ethanol fermentation of the cellulosic fraction of sugarcane bagasse. Bioresource Technol. 2015;191:312-21.

29. Hernández-Beltrán JU, Hernández-Escoto H. Enzymatic hydrolysis of biomass at high-solids loadings through fed-batch operation. Biomass Bioenerg. 2018;119:191-7.

30. Godoy CMD, Machado DL, Costa ACD. Batch and fed-batch enzymatic hydrolysis of pretreated sugarcane bagasse-assays and modeling. Fuel. 2019;253:392-9.

31. Sluiter JB, Ruiz RO, Scarlata CJ, Sluiter AD, Templeton DW. Compositional analysis of lignocellulosic feedstocks. 1. Review and description of methods. J Agr Food Chem. 2010;58(16):9043-53.

32. Zhou X, Xu Y. Eco-friendly consolidated process for co-production of xylooligosaccharides and fermentable sugars using self-providing xylonic acid as key pretreatment catalyst. Biotechnol Biofuels. 2019. https://doi. org/10.1186/s13068-019-1614-5.

33. Xu Y, Fan L, Wang X, Yong Q, Yu S. Simultaneous separation and quantification of linear xylo- and cello-oligosaccharides mixtures in lignocellulosics processing products on high-performance anion-exchange chromatography coupled with pulsed amperometric detection. BioResources. 2013:8(3):3247-59.

\section{Publisher's Note}

Springer Nature remains neutral with regard to jurisdictional claims in published maps and institutional affiliations.
Ready to submit your research? Choose BMC and benefit from:

- fast, convenient online submission

- thorough peer review by experienced researchers in your field

- rapid publication on acceptance

- support for research data, including large and complex data types

- gold Open Access which fosters wider collaboration and increased citations

- maximum visibility for your research: over 100M website views per year

At $\mathrm{BMC}$, research is always in progress.

Learn more biomedcentral.com/submissions 